\title{
Exercise training program based on minimum weekly frequencies: effects on blood pressure and physical fitness in elderly hypertensive patients
}

\section{Programa de exercícios físicos baseado em frequência semanal mínima: efeitos} na pressão arterial e aptidão física em idosos hipertensos

Wilson M. De Moraes',2, Pamella R. M. Souza³, Mônica H. N. P. Pinheiro², Maria C. Irigoyen³, Alessandra Medeiros4, Marcia K. Koike

\begin{abstract}
Background: Exercise training (ET) can reduce blood pressure (BP) and prevent functional disability. However, the effects of low volumes of training have been poorly studied, especially in elderly hypertensive patients. Objectives: To investigate the effects of a multi-component ET program (aerobic training, strength, flexibility, and balance) on BP, physical fitness, and functional ability of elderly hypertensive patients. Methods: Thirty-six elderly hypertensive patients with optimal clinical treatment underwent a multi-component ET program: two 60-minute sessions a week for 12 weeks at a Basic Health Unit. Results: Compared to pre-training values, systolic and diastolic BP were reduced by $3.6 \%$ and $1.2 \%$, respectively $(p<0.001)$, body mass index was reduced by $1.1 \%(p<0.001)$, and peripheral blood glucose was reduced by $2.5 \%(p=0.002)$. There were improvements in all physical fitness domains: muscle strength (chair-stand test and elbow flexor test; $p<0.001$ ), static balance test (unipedal stance test; $p<0.029$ ), aerobic capacity (stationary gait test; $p<0.001$ ), except for flexibility (sit and reach test). Moreover, there was a reduction in the time required to perform two functional ability tests: "put on sock" and "sit down, stand up, and move around the house" $(p<0.001)$. Conclusions: Lower volumes of ET improved BP, metabolic parameters, and physical fitness and reflected in the functional ability of elderly hypertensive patients. Trial Registration RBR-2xgjh3
\end{abstract}

Keywords: hypertension; exercise; physical fitness; rehabilitation; elderly.

\section{Resumo}

Contextualização: O treinamento físico (TF) é capaz de reduzir a pressão arterial (PA) e prevenir o declínio da capacidade funcional. Entretanto, pouco tem sido estudado sobre os efeitos de menores volumes de treinamento em idosos com hipertensão arterial (HA) Objetivos: Investigar os efeitos de um programa de TF multicomponente (treinamento aeróbico, força, flexibilidade e equilíbrio) na PA aptidão física e capacidade funcional de idosos com HA. Métodos: Trinta e seis idosos com HA e tratamento clínico otimizado foram submetidos a um programa de exercícios físicos multicomponente, com duas sessões semanais de 60 minutos cada, durante 12 semanas, em uma Unidade Básica de Saúde (UBS). Resultados: Comparados aos valores antes do TF, observou-se redução de 3,6\% da PA sistólica ( $p<0,001)$, de 1,2\% da PA diastólica ( $p<0,001)$, de 1,1\% do índice de massa corporal (IMC) ( $p<0,001)$ e de 2,5\% da glicemia periférica em jejum ( $p=0,002)$. Observou-se melhora em todos os domínios da aptidão física, como força muscular (testes de levantar da cadeira e flexão de cotovelos, $p<0,001$ ); equilíbrio estático (teste de apoio unipodal, $p=0,029$ ) capacidade aeróbica (teste de marcha estacionária, $p<0,001$ ), com exceção da flexibilidade (teste de sentar e alcançar). Além disso, houve redução no tempo utilizado para realização de dois testes de avaliação da capacidade funcional, o de "calçar meias" e o de "sentar, levantar-se da cadeira e locomover-se pela casa" ( $p<0,001)$. Conclusões: O TF com duas sessões semanais em idosos hipertensos repercutiu na melhora dos indicadores metabólicos, da aptidão física e da capacidade funcional e atuou como auxiliar no controle da PA. Registro de Ensaios Clínicos RBR-2xgjh3.

Palavras-chave: hipertensão; exercício físico; aptidão física, reabilitação, idoso

\section{Received: 05/15/2011 - Revised: 08/10/2011 - Accepted: 08/30/2011}

\footnotetext{
School of Physical Education and Sport, Universidade de São Paulo (USP), São Paulo, SP, Brazil

${ }^{2}$ Health Sciences Center, Universidade de Fortaleza (UNIFOR), Fortaleza, CE, Brazil

${ }^{3}$ Laboratory of Experimental Hypertension, Medical School, USP, São Paulo, SP, Brazil

${ }^{4}$ Department of Biosciences, Universidade Federal de São Paulo (UNIFESP), Santos, SP, Brazi

${ }^{5}$ Emergency Medicine Research Laboratory, Departament of Internal Medicine, Medical School, USP, São Paulo, SP, Brazil

Correspondence to: Marcia K. Koike, Rua Catulo P. Cearense, n²97, apto 122, Bairro Vila da Saúde, CEP 04145-010, São Paulo, SP, Brasil, e-mail: mkoike2011@gmail.com
} 


\section{Introduction $: \because$.}

Arterial hypertension (AH) is a multi-causal and multifactorial syndrome characterized by high and sustained levels of blood pressure (BP), associated with target-organ damage. It is a major risk factor for coronary artery disease, stroke, myocardial infarction, heart failure, and chronic renal failure, considerably increasing the risk of cardiovascular mortality ${ }^{1,2}$. Cardiovascular diseases are the main cause of death in Brazil, posing a serious public health problem due to its high morbidity and the high costs resulting from treatment and complications ${ }^{3,4}$.

In Brazil, according to a recent survey by the Ministry of Health, the prevalence of $\mathrm{AH}$ is greater than $50 \%$ among the elderly population, which makes it the most prevalent chronic disease in this segment of the population ${ }^{5}$. Population projections estimate that the elderly population will increase about threefold between 2010 and 2030, growing from the current 13.2 million to 40 million people ${ }^{6}$. Thus, in the coming years, we will have the challenge of living with an increasing number of elderly, and possibly hypertensive, people, supporting the need for more effective therapeutic approaches, both pharmacological and non-pharmacological.

Exercise is part of the non-pharmacological conduct for $\mathrm{AH}$ treatment as it can reduce pressure levels ${ }^{7,8}$ and the risk factors associated with $\mathrm{AH}$, such as obesity, insulin resistance, and dyslipidemia ${ }^{2,4}$. Consequently, there is a considerable reduction in costs with tests and medication ${ }^{9}$. Exercise programs are particularly important to elderly hypertensive patients because they are subject not only to the effects of $\mathrm{AH}$ (e.g. the decline in functional ability ${ }^{10,12}$ ) but also to physical limitations inherent in advancing age ${ }^{12,13}$. Elderly hypertensive patients have an odds ratio 4.2 times higher of developing functional limitations ${ }^{12}$ or they are $39 \%$ more likely to become dependent in activities of daily living than normotensive people ${ }^{11}$.

There is evidence that the assumption of a more active lifestyle is associated with the prevention or attenuation of functional limitations, AH, and physical fitness ${ }^{7,13}$. Therefore, in addition to the effects on BP reduction and associated factors, exercise can prevent the decline in functional ability and improve the performance of elderly people in daily activities, thus improving quality of life even in the presence of a pathological chronic condition ${ }^{11}$. Based on the main recommendations for the hypertensive population, the minimum weekly frequency for exercise is three sessions, and higher the weekly frequency ${ }^{4,7}$, greater the benefit. In contrast to these recommendations, the elderly are the most insufficiently active part of the Brazilian population ${ }^{5}$, leading to the conclusion that few elderly people with $\mathrm{AH}$ benefit from this therapeutic approach.
In order for this population to actually benefit from the effects of exercise training (ET), there must be adherence to the programs. It is known that high amounts of ET are associated with low adherence to exercise ${ }^{14}$. In contrast, studies have shown that exercise programs with reduced frequency (e.g. twice-weekly sessions) provide a significant reduction in systolic BP (SBP) and diastolic BP (DBP) $)^{8,15}$. In addition, two weekly exercise sessions are sufficient to promote improved functional ability in elderly people ${ }^{16}$. The aim of the present study was to assess the effects of an exercise program of twiceweekly sessions for 12 weeks on the BP, physical fitness, and functional ability of elderly hypertensive patients.

\section{Methods $: \because$.}

The study is characterized as a quasi-experimental noncontrolled study, and it was conducted with a group of elderly participants ( $\geq 60$ years) diagnosed with $\mathrm{AH}$, assisted at a Basic Health Unit (BHU) in the city of Fortaleza, CE, Brazil. The data collection took place at the Luíza Távora Community Center, belonging to the Secretariat for Social Action. Initially, 44 participants who attended the Community Center to perform recreational activities were selected. All participants received the necessary information about the study and filled in and signed a consent form. The research protocol was approved by the Research Ethics Committee of Universidade de Fortaleza (UNIFOR), Fortaleza, CE, Brazil, under protocol number 120/2207.

The following exclusion criteria were established: less than $80 \%$ participation in exercise sessions; participation in another ET program; inability to understand the instructions due to cognitive problems; uncontrolled hypertension (>160/100 mmHg); reports of chest pain; dizziness or discomfort; bone, muscle or joint problems or any other previous condition that would preclude participation in the exercise program. A structured questionnaire was used to collect socioeconomic data, the existence of risk factors for cardiovascular disease, and the presence of comorbidities. The data were supplemented with information obtained from individual registration forms from the BHU.

Peripheral blood glucose, BP at rest, and body mass index (BMI) were measured before and after the ET program. Glucose was measured with an Accu-Chek Go ${ }^{\circledR}$ kit and BP levels, with a Missour $i^{\circledR}$ column sphygmomanometer and a Rappaport stethoscope $^{\circledR}$. The BP was measured with the participant in the sitting position, and the mean of three measurements taken from the left arm was considered for analysis. BMI was calculated by dividing the body weight in kilograms by the square of the height in meters. The same variables were assessed 96 hours after the 
last exercise session (post-ET program measure) in order to avoid the acute effects of the last session on the BP level.

Physical fitness was assessed through indicators of upper and lower limb muscle strength, flexibility, balance, and aerobic capacity. Functional ability was assessed by tests that simulate movements and actions often carried out in everyday life. For the time-dependent measures, a CASIO stopwatch model HS-80TW-1DF was used.

Lower limb muscle strength was determined by the chairstand test $(\mathrm{CST})^{17}$, in which the participant sat on a chair with a seat height of $43 \mathrm{~cm}$, feet flat on the floor, and arms folded across the chest. At the signal, the participant got up and then sat again. Upper limb muscle strength was assessed by the elbow flexor test $(\mathrm{EFT})^{17}$. The participant sat on a chair, starting with arms to the side, and performed elbow flexion and extension cycles holding a dumbbell weighing $2 \mathrm{~kg}$ (women) or $4 \mathrm{~kg}$ (males). For the CST and EFT scores, we considered the highest number of full cycles performed during a 30-second period.

Flexibility was assessed by the sit and reach test (SRT) ${ }^{17}$ and consisted of sitting on a chair with a seat height of $43 \mathrm{~cm}$ and extending the knee of the dominant limb forward, with the other knee flexed at $90^{\circ}$. At the signal, the participants raised their arms, placed one hand over the other, and brought their arms forward, trying to touch the toes of the extended limb. Using a ruler, the distance $(\mathrm{cm})$ between the hallux and the farthest point reached by the hands was measured, with zero being the end of the hallux. When the participants did not exceed the hallux, the negative sign was added to the score obtained; when the participants exceeded the hallux, a positive sign was added.

Aerobic capacity was measured using the stationary gait test $(\mathrm{SGT})^{17}$, in which the participant initiated knee flexion, simulating gait while standing in place. Participants had to bring the knees midway between the patella and the contralateral iliac crest. The result was the total number of steps taken during a 2-minute period.

Balance was assessed using the unipedal stance test (UST) with eyes open ${ }^{18}$. The participants stood with hands on their hips and gazing at a fixed point 2 meters ahead and, at the signal, raised one foot up to the height of the opposite knee and tried to maintain that position. The highest value of three attempts was used, in seconds.

To assess functional ability, the sit down, stand up, and move around the house test (SSMT) and the put on sock test $(\mathrm{PST}){ }^{19}$ were used. The SSMT consisted of walking around two cones twice alternating turns to the right and to the left. The shortest time taken to achieve the full itinerary, in seconds, was used as a result. The PST consisted of the time, in seconds, taken to put on one sock while sitting on a chair with a seat 40 $\mathrm{cm}$ in height and knees flexed.
All participants were familiarized with the motor tests prior to the first assessment. The application of the tests was divided between assessors who were not involved in the intervention. The test-retest analysis showed an Intrarater Correlation Coefficient of 0.86 for DBP and 0.87 for SBP, with measurements performed at two-day intervals at the same time and place.

The ET program consisted of twice-weekly sessions over a period of 12 weeks. Of the initial 44 participants, 36 completed the program. The participants were divided into two classes to better control the performance of voluntary movements by the trainers/instructors (three per session). The "multi-component" sessions lasted approximately 60 minutes and were composed of a warm-up period followed by stretching ( \pm 10 minutes); the main part (35 to 40 minutes) consisting of approximately 20 minutes of walking with the remaining time dedicated to dance, alternating strength exercises with dumbbells and rods; and finally, a cool-down activity with 10 minutes of stretching.

The sessions were conducted with moderate intensity according to the Perceived Exertion Scale, which corresponds to a score between 4 and 6 on a scale of 0 to 10 with 0 being the lowest level of exertion. Some participants had to be trained to understand the application of this scale. There was no change in the pharmacological treatment regimen for participants during the study, and they were referred to medical reassessment after the program.

The results were analyzed using SigmaStat for Windows (Systat Software Inc., version 3.10). The clinical and sociodemographic characteristics are expressed in absolute frequency and/or relative frequency. Metabolic, physical fitness, and functional ability indicators are expressed as mean \pm standard deviation or median (interquartile interval). After the Kolmogorov-Smirnov normality test, the pre- and post-ET moments were compared using the Student paired t test or the Wilcoxon signed rank test. The physical fitness tests were compared with reference values of "normality" by gender and age ${ }^{20,21}$. The significance level of $\mathrm{p}<0.05$ was adopted. Simple linear regression analysis was used to investigate associations between the level of initial BP and the reduction in BP after ET.

\section{Results $: \because$ 。}

Thirty-six participants who completed the protocol were analyzed. The mean age was 69.3 years, and 11 (30.6\%) participants were male. Regarding the associated risk factors or comorbidities, 16 participants (44.4\%) had some type of dyslipidemia; 17 $(47.2 \%)$ were obese $\left(\mathrm{BMI}>27 \mathrm{~kg} / \mathrm{m}^{2}\right)$; eight $(22.2 \%)$ had diabetes mellitus type 2; four (8.9\%) suffered from alcoholism; and six (13.3\%) were smokers. The clinical and sociodemographic characteristics of the participants are described in Table 1. 
Compared to the pre-ET program period, there was a reduction of $1.4 \%$ in body mass ( $\mathrm{p}<0.001)$ in 30 participants $(83 \%)$ and a reduction of about $4.8 \%$ in fasting blood glucose $(\mathrm{p}=0.002)$ in 28 participants (78\%). The mean values for body mass, BMI, and blood glucose are shown in Table 2. At the end of the ET program, 32 participants (89\%) showed a reduction of about $6 \mathrm{mmHg}$ in SBP $(\mathrm{p}<0.001)$, and $23(64 \%)$ showed a reduction of about $2 \mathrm{mmHg}$ in DBP $(\mathrm{p}<0.001)$ (Figure 1). The change in the levels of SBP and DBP correlated with baseline SBP and DBP, respectively, suggesting that the higher the SBP and DBP, the greater

Table 1. Sociodemographic and clinical characteristics of participants of a twice-weekly exercise program.

\begin{tabular}{lcc}
\hline Variables & $\begin{array}{c}\text { Absolute } \\
\text { frequency }(\mathrm{n})\end{array}$ & $\begin{array}{c}\text { Relative fre- } \\
\text { quency (\%) }\end{array}$ \\
\hline Pharmacologic Treatment & 34 & 88.9 \\
\hline ACEls & 8 & 22.2 \\
\hline Beta blockers & 11 & 30.6 \\
\hline Diuretics & 2 & 5.6 \\
\hline Calcium channel blockers & 11 & 30.6 \\
\hline Statins & 4 & 11.1 \\
\hline Aspirin & 8 & 22.2 \\
\hline Oral hypoglycemic drugs & & \\
\hline Educational level & 14 & 38.9 \\
\hline$\quad$ Illiterate & 22 & 61.9 \\
\hline Elementary school & & \\
\hline Income & & \\
\hline$<1$ MW & 26 & 76.5 \\
\hline Between 1 and 2 MW & 7 & 20.6 \\
\hline$>3$ MW & 1 & 2.9 \\
\hline
\end{tabular}

ACEls=angiotensin-converting enzyme inhibitors; $\mathrm{MW}=$ minimum wage; ${ }^{\dagger}$ Two participants chose not to disclose their income; data concerning income $n=34$. the effects on these variables with the exercise training (Figure 2). Although SBP and DBP correlated positively and linearly with body mass in the pre-exercise period $(\mathrm{r}=0.34, \mathrm{p}=0.04$; $\mathrm{r}=0.43$ and $\mathrm{p}=0.009$, respectively), this correlation was not maintained in the changes in these variables after the intervention.

The data for the physical capacity assessed pre- and post-ET program are shown in Table 2. ET promoted an increase $(\mathrm{p}<0.001)$ in the performance of upper and lower limb muscle strength motor tests, expressed by the increase in the number of repetitions achieved in the CST and in the EFT. At the beginning of the protocol, 21 participants (58.3\%) were included in the reference standards of normality for gender and age in the CST and in the EFT and, at the end of the protocol, this number increased to $26(72.2 \%)$.

The ET did not affect flexibility, estimated by the SRT. Initially, only 22 participants $(61.1 \%)$ were below the reference values, and this frequency remained the same after the intervention. There was improvement in aerobic capacity $(\mathrm{p}<0.001)$ and balance $(\mathrm{p}=0.029)$, demonstrated by the increase in the number of steps and by the duration of unipedal stance, respectively. For the UST and SGT, 16 participants (44.4\%) showed results within normality reference values, rising to $24(66.7 \%)$ at the end of the protocol for the SGT and 20 (55.6\%) for the UST.

The improvement in functional ability was verified by the reduction in the time taken in the PST and in the SSMT (Figure 3 ), with changes of $16.3 \%$ for the PST ( $p<0.001)$ and $2 \%$ for the SSMT ( $<<0.001)$. In the PST, 35 participants $(97.2 \%)$ improved their performance and 28 (77.8\%) in the SSMT. Throughout the intervention period, there were no reports of accident or injury by the participants.

Table 2. Effects of exercise program on anthropometric characteristics, blood glucose concentration, and physical ability of elderly participants with hypertension treated at a Basic Health Unit in Fortaleza, CE, Brazil, 2007-2008.

\begin{tabular}{|c|c|c|c|}
\hline Parameters & Pre & Post & $p$ value \\
\hline Body mass (kg) & $72.1 \pm 10.4$ & $71.2 \pm 10.1$ & $<0.001$ \\
\hline BMI $\left(\mathrm{kg} / \mathrm{m}^{2}\right)$ & $27.9 \pm 4.2$ & $27.6 \pm 4.1$ & $<0.001$ \\
\hline Blood glucose (mg/dL) & $104.6 \pm 16.5$ & $101.6 \pm 13.8$ & 0.002 \\
\hline \multicolumn{4}{|l|}{ Physical ability } \\
\hline \multicolumn{4}{|l|}{ Muscle strength } \\
\hline CST (repetitions) & $10.0(8.5-11.0)$ & $11.0(9.0-12.0)$ & $<0.001$ \\
\hline EFT (repetitions) & $12.5(11.0-14.0)$ & $14.0(12.5-15.5)$ & $<0.001$ \\
\hline \multicolumn{4}{|l|}{ Flexibility } \\
\hline SRT (centimeters) & $-2.85[(-4.25)-(-1.60)]$ & $-2.90[(-4.20)-(-1.40)]$ & NS \\
\hline \multicolumn{4}{|l|}{ Aerobic capacity } \\
\hline SGT (number of steps) & $73.9 \pm 10.8$ & $78.3 \pm 9.8$ & $<0.001$ \\
\hline \multicolumn{4}{|l|}{ Balance } \\
\hline UST (seconds) & $8.7 \pm 3.4$ & $9.2 \pm 3.1$ & 0.029 \\
\hline
\end{tabular}

$\mathrm{BMI}=$ Body mass index; CST=chair-stand test; EFT=elbow flexor test; $\mathrm{SRT}=$ sit and reach test; $\mathrm{SGT}=$ Stationary gait test; UST=unipedal stance test; NS=Non-significant ( $>0.05$ ); data analyzed using the paired $t$-test and shown as mean $\pm S D$ or analyzed using the Wilcoxon signed rank test and shown as median values (interquartile intervals). 

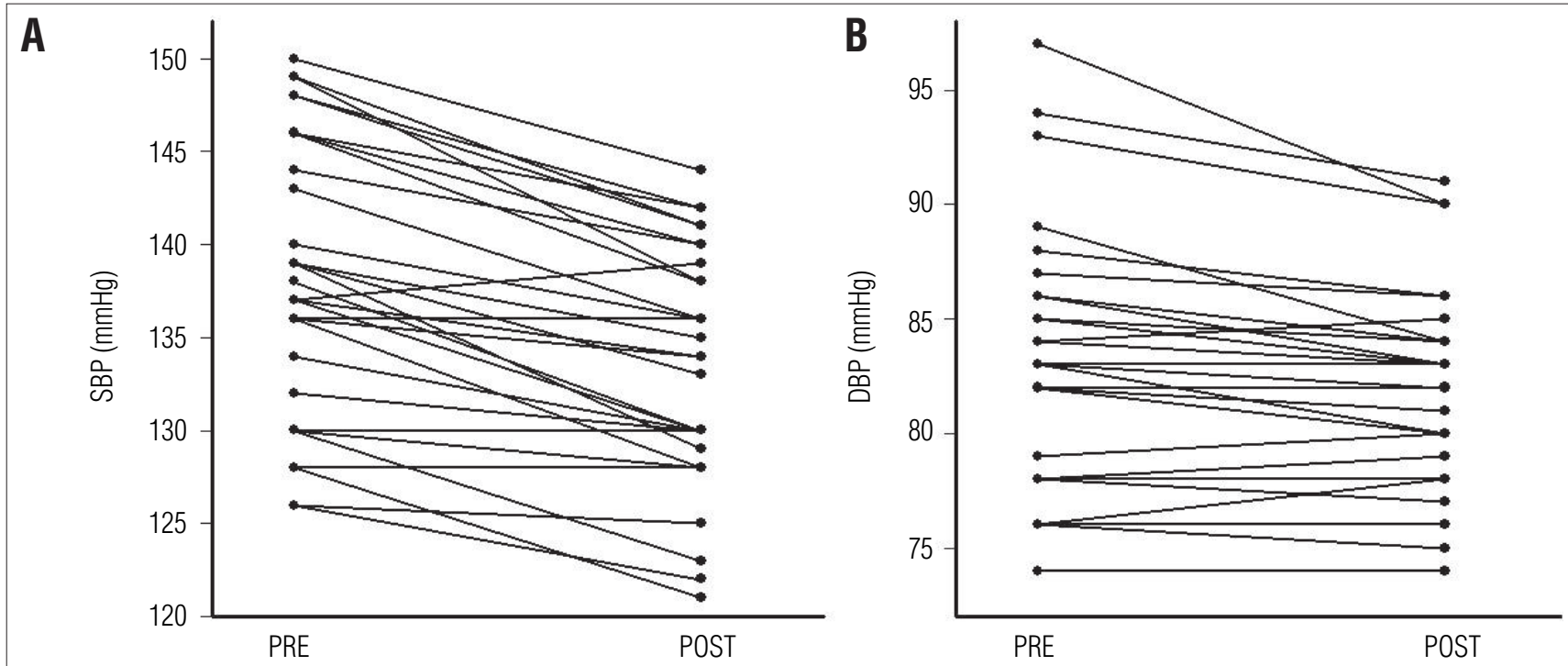

Panel A: Systolic blood pressure (SBP) and Panel B: Diastolic blood pressure (DBP). Wilcoxon signed rank test.

Figure 1. Blood pressure levels in elderly hypertensive participants undergoing a twice-weekly exercise program.

\section{A}

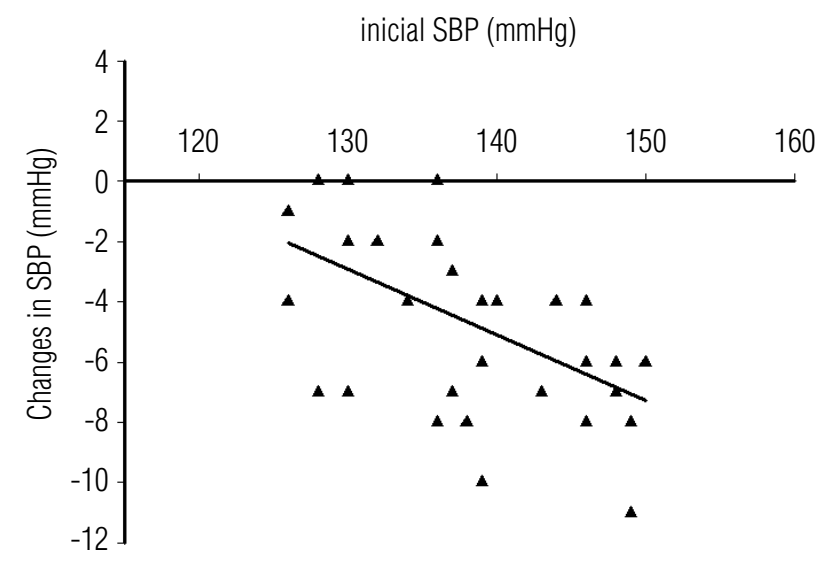

B

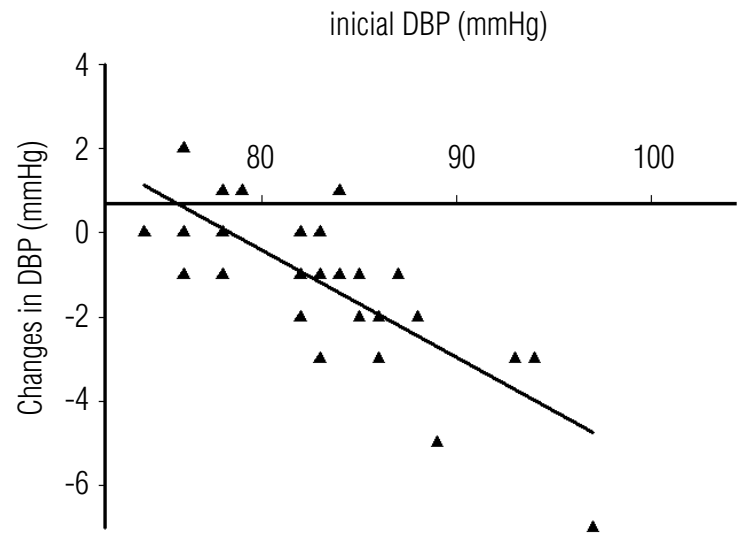

Figure 2. Correlation between baseline and absolute changes to systolic blood pressure (SBP, $m m H g, y=25.518-0.219 x, r=0.507, p=0.002$, panel A) and diastolic blood pressure (DBP, $\mathrm{mmHg}, \mathrm{y}=20.103-0.256 \mathrm{x}, \mathrm{r}=0.762, \mathrm{p}<0.001$, panel $\mathrm{B}$ ) in elderly participants with hypertension $(n=36)$ after a 12-week exercise program.
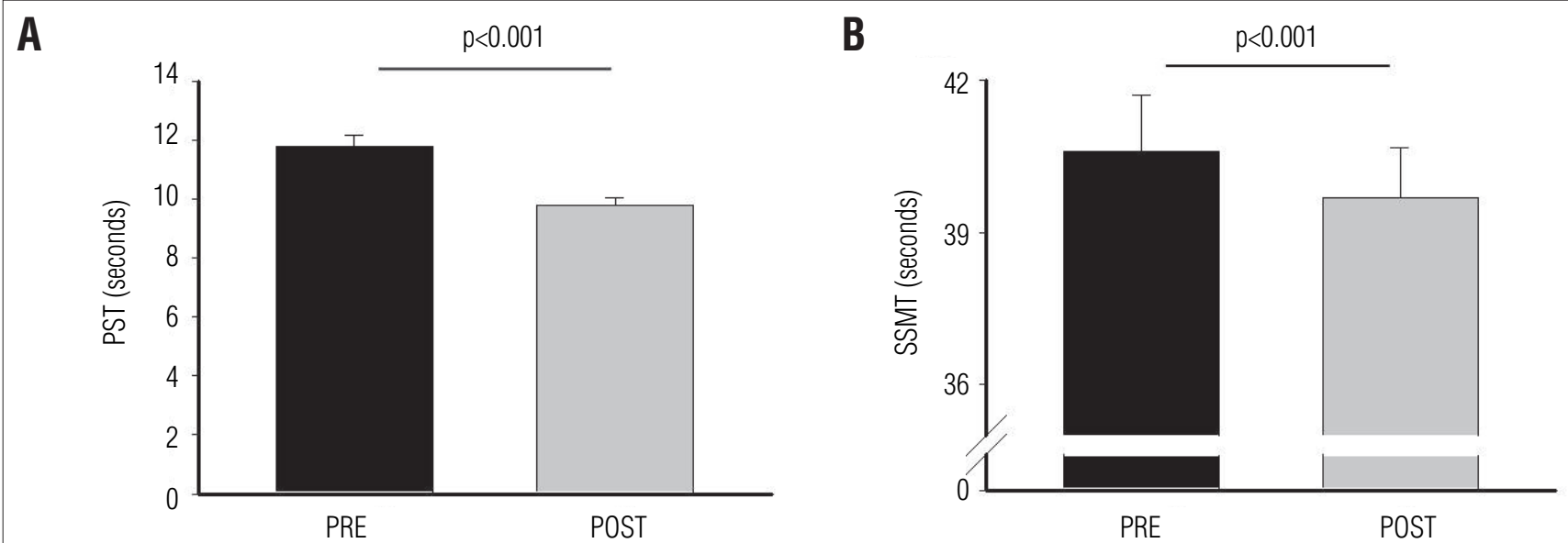

Panel A: Put on Sock Test (PST). Panel B: Sit, Stand up, and Move around the house Test (SSMT). Results are expressed as mean \pm SEM. Paired t test. Shorter times represent better performance.

Figure 3. Performance in functional ability tests before and after a twice-weekly exercise program. 


\section{Discussion $: \because$.}

The results demonstrated that a multi-component ET program with reduced weekly frequency can contribute to the reduction in BMI, blood glucose, and BP and can improve the physical fitness and functional ability of elderly hypertensive patients under pharmacological treatment. AH is a significant risk factor for cardiovascular disease, affecting more frequently the elderly population ${ }^{4}$. It is characterized by various metabolic dysfunctions $\mathrm{s}^{1,4}$ and usually accompanied by obesity ${ }^{22,23}$. Some of the hypotensive mechanisms of ET are indirect, such as reduction in body weight and blood glucose levels ${ }^{7}$, which in the present study was small but significant. The reduction found in the peripheral blood glucose after intervention was similar to that found in a ET protocol with a greater number of weekly sessions ${ }^{24}$, and even other programs with a higher volume of ET did not reduce the anthropometric parameters ${ }^{24,25}$.

Although elderly participants with hypertension had a lower BP reduction after ET compared to young and middleaged individuals, there was the benefit of the hypotensive effect of exercise ${ }^{26}$. This effect is well known, but there is no consensus on the optimum amount of exercise to induce greater hypotensive effects. Some studies have shown that ET, even with a reduced frequency of only twice a week or volumes less than 120 minutes a week, promotes a mean reduction of 2.8 and $2.2 \mathrm{mmHg}$ in SBP and DBP, respectively ${ }^{8}$. Furthermore, no additional hypotensive effect is observed when participants exercise more than 60 minutes per week ${ }^{15}$. Our results corroborate these findings, considering that the volume of two training sessions in our protocol amounted to about 120 minutes per week.

In addition to indirect effects, such as improvement in glucose metabolism and body mass reduction, the ET causes a reduction in peripheral vascular resistance, cardiac output, sympathetic nerve activity, plasma volume, and endothelial function ${ }^{7}$. These may be the mechanisms responsible for hypotension, the magnitude of which depends on the initial levels of SBP and DBP, therefore the higher the initial BP levels, the greater the reductions obtained ${ }^{7,15,24}$. The results of our study confirm this assertion. It should also be emphasized that the reduction in BP during this period may have suffered interference from other factors, such as emotional state, diet, and proper use of medication.

First, it is interesting to note that the results of motor tests showed that a reasonable number of elderly participants had results below the reference values for gender and age and with lower mean values than elderly participants without $\mathrm{AH}^{18,20}$. However, these results were similar to or slightly lower than the results from other studies involving elderly patients with $\mathrm{AH}^{27,28}$, which suggests that $\mathrm{AH}$ is a chronic condition that can be associated with decreased motor capacity and physical fitness. Second, it is also interesting that the exercise protocol was effective in quantitatively improving the performance of muscle strength, balance, and aerobic capacity tests, as well as increasing the frequency of participants who achieved the range of reference values for muscle strength and aerobic capacity ${ }^{20}$.

The fact that flexibility did not show a clear improvement can be justified by the low volume of training specific to this physical capacity, far below the training performed by Monteiro et al. ${ }^{24}$ who dedicated 30 minutes of each session, three times a week, to flexibility training in hypertensive elderly participants in a BHU. Considering that one of the objectives of our study was to have only two weekly sessions, the solution would be to dedicate more time to flexibility training. Systematic exercise programs based on strength, balance, and walking activities decreased the incidence of falls ${ }^{29}$, a frequent problem among the elderly. The improvement in muscle strength and static balance after the intervention was probably due to the fact that the exercise protocol included muscle strength exercises and dance activities, in which balance skills are implicit.

The stationary gait test (SGT) was used in the present study to assess aerobic capacity and was chosen because it can be applied in a small room without expensive equipment. The SGT also showed a positive correlation with other tests for the same estimate ${ }^{28}$. Other studies have found significant improvements in aerobic capacity with exercise in elderly participants with $\mathrm{AH}^{15,23}$, which may result from several factors including improvement in cardiac output, increased peripheral blood flow and/or improvement in musculoskeletal metabolism? .

Given that elderly patients with less muscle strength, aerobic capacity, flexibility, and balance have more difficulty performing daily tasks ${ }^{13,16,19,30}$, two motor tests were used to compare the maximum capacity of task performance with everyday activities and to determine whether the improvement in these physical skills could have an effect on functional ability. The first test was the PST, which emphasizes personal care based on the participant's ability to put on socks. It was not common for the population of the present study to wear socks in a tropical climate, but it became normal because it was necessary for exercise. The second test was the SSMT, which emphasizes activities of locomotion, simulating the actions of sitting, standing up from a chair, and walking around the house ${ }^{19}$.

Training improved the results of both tests, most prominently the PST. No studies were found involving elderly 
patients with $\mathrm{AH}$ that applied these tests, however Cosme, Okuma, and Mochizuki ${ }^{31}$ showed that elderly individuals who exercise regularly have excellent performance in the PST and the SSMT, showing that ET can have a positive impact on these skills as occurred in our study. The improvement in task performance times may have direct implications for the functional ability of the elderly, considering that some activities can become extremely complex such as putting on a sock ${ }^{19}$ or crossing a busy road due to slower gait and reduced safety at road-crossings ${ }^{32}$.

The use of ambulatory blood pressure monitoring (ABPM) could have provided more reliable BP measures; however, the intrarater coefficients for SBP and DBP indicated reproducibility. Other limiting factors of our study were the lack of prescription of exercise based on cardiopulmonary exercise tests and the lack of a control group, which hampered comprehensive comparative analysis. Nevertheless, we should consider, on one hand, the absence of local conditions for sophisticated tests and, on the other hand, the practicality of the program location, which the elderly participants already frequented and which may have contributed to the high commitment to the ET program $(82 \%$ of the participants completed the protocol). This aspect is particularly interesting given that the studied sample had a low level of education, a limiting factor to the recognition of the importance of exercise and adherence to hypertensive treatments ${ }^{22}$.
Exercise programs with hypertensive patients have been investigated frequently, most of them conducted in environments such as hospitals and clinics that allow stricter control over the participants, however very little has been investigated on the inclusion of programs in community settings such as the BHU. The few attempts to that effect showed promising results ${ }^{24,33}$.

In summary, the results suggest that a multi-component ET protocol, based on twice-weekly frequency, may have contributed to reduction in BP, BMI, and blood glucose levels, and the increase in muscle strength, aerobic capacity, and balance, resulting in improved functional ability. Some changes, though subtle, occurred in the majority of the participants, which can be advantageous considering the low adherence of part of the elderly population to more intensive exercise programs. Rehabilitation professionals should evaluate the various therapeutic possibilities, taking into consideration the main evidence-based recommendations, the scarcity of sophisticated resources, and the low adherence to non-pharmacological $\mathrm{AH}$ treatment commonly found in Primary Health.

\section{Acknowledgments $\because \because$.}

To Roseclea Barbosa and to Emílio Praxedes for their assistance in data collection.

\section{References}

1. Williams SM. Endophenotypes, heritability, and underlying complexity in hypertension. Am J Hypertens. 2010;23(8):819.

2. Chobanian AV, Bakris GL, Black HR, Cushman WC, Green LA, Izzo JL Jr, et al. Seventh report of the joint National Committee on Prevention, Detection, Evaluation, and Treatment of High Blood Pressure. Hypertension. 2003;42(6):1206-52.

3. Azambuja MI, Foppa M, Maranhão MF, Achutti AC. Economic burden of severe cardiovascular diseases in Brazil: an estimate based on secondary data. Arq Bras Cardiol. 2008;91(3):148-55, 163-71.

4. Sociedade Brasileira de Cardiologia; Sociedade Brasileira de Hipertensão; Sociedade Brasileira de Nefrologia. VI Brazilian Guidelines on Hypertension. Arq Bras Cardiol. 2010;95(1 Suppl):1-51.

5. Ministério da Saúde [homepage na Internet]. Vigitel Brasil 2009: vigilância de fatores de risco e proteção para doenças crônicas por inquérito telefônico. Brasilia: Ministério da Saúde, 2010. [acesso em 2011 Fev 25]. Disponível em: www.saude.gov.br/svs.

6. Instituto Brasileiro de Geografia e Estatística (IBGE) [homepage na Internet]. Projeção da população do Brasil por sexo e idade - 1980-2050. Revisão 2008. Rio de Janeiro: IBGE-DEPIS [acesso em 2011 Fev 21]. Disponível em: www.ibge.gov.br.

7. Pescatello LS, Franklin BA, Fagard R, Farquhar WB, Kelley GA, Ray CA, et al. American College of Sports Medicine position stand. Exercise and hypertension. Med Sci Sports Exerc. 2004;36(3):533-53

8. Whelton $\mathrm{SP}, \mathrm{Chin} \mathrm{A}$, Xin X, He J. Effect of aerobic exercise on blood pressure: a meta-analysis of randomized, controlled trials. Ann Intern Med. 2002;136(7):493-503.

9. Rolim RMC, Amaral SL, Monteiro HL. Hipertensão e exercício: custos do tratamento ambulatorial, antes e após a adoção da pratica regular e orientada de condicionamento físico. Hipertensão. 2007; 10(2):54-61.
10. Hajjar I, Lackland DT, Cupples LA, Lipsitz LA. Association between concurrent and remote blood pressure and disability in older adults. Hypertension. 2007;50(6):1026-32.

11. Alves $L C$, Leimann $B C Q$, Vasconcelos MEL, Carvalho MS, Vasconcelos AGG, Fonseca TCO, et al. A influência das doenças crônicas na capacidade funcional dos idosos do Município de São Paulo, Brasil. Cad Saúde Pública. 2007;23(8):1924-30.

12. Virtuoso Júnior JS, Guerra RO. Factors associated to functional limitations in elderly of low income. Rev Assoc Med Bras. 2008;54(5):430-5.

13. American College of Sports Medicine; Chodzko-Zajko WJ, Proctor DN, Fiatarone Singh MA Minson CT, Nigg CR, et al. American College of Sports Medicine position stand. Exercise and physical activity for older adults. Med Sci Sports Exerc. 2009;41(7):1510-30.

14. Baker MK, Kennedy DJ, Bohle PL, Campbell DS, Knapman L, Grady J, et al. Efficacy and feasibility of a novel tri-modal robust exercise prescription in a retirement community: a randomized, controlled trial. J Am Geriatr Soc. 2007;55(1):1-10.

15. Ishikawa-Takata $\mathrm{K}$, Ohta $\mathrm{T}$, Tanaka $\mathrm{H}$. How much exercise is required to reduce blood pressure in essential hypertensives: a dose-response study. Am J Hypertens. 2003;16(8):629-33.

16. Carvalho MJ, Marques E, Mota J. Training and detraining effects on functional fitness after a multicomponent training in older women. Gerontology. 2009;55(1):41-8.

17. Rikli RE, Jones CJ. Development and validation of a functional fitness test for communityresiding older adults. J Aging Phys Act. 1999;7(2):129-61.

18. Gustafson AS, Noaksson L, Kronhed AC, Möller M, Möller C. Changes in balance performance in physically active elderly people aged $73-80$. Scand J Rehabil Med 2000;32(4):168-72. 
19. Andreotti RA, Okuma SS. Validação de uma bateria de testes de atividades da vida diária para idosos fisicamente independentes. Rev Paul Educ Fís. 1999;13(1):46-66.

20. Rikli RE, Jones CJ. Functional fitness normative scores for community-residing older adults, ages 60-94. J Aging Phys Act. 1999;7(3):162-81.

21. Springer BA, Marin R, Cyhan T, Roberts H, Gill NW. Normative values for the unipedal stance test with eyes open and closed. J Geriatr Phys Ther. 2007;30(1):8-15.

22. Zaitune MPA, Barros MBA, César CLG, Carandina L, Goldbaum M. Arterial hypertension in the elderly: prevalence, associated factors, and control practices in Campinas, São Paulo, Brazil. Cad Saúde Pública. 2006;22(2):285-94.

23. Barone BB, Wang NY, Bacher AC, Stewart KJ. Decreased exercise blood pressure in older adults after exercise training: contributions of increased fitness and decreased fatness. Br J Sports Med. 2009;43(1):52-6.

24. Monteiro HL, Rolim LMC, Squinca DA, Silva FC, Ticianeli CCC, Amaral SL. Efetividade de um programa de exercícios no condicionamento físico, perfil metabólico e pressão arterial de pacientes hipertensos. Rev Bras Med Esporte. 2007;13(2):107-12.

25. Oliveira KPC, Vieira EL, Oliveira JD, Oliveira KR, Lopes FJG, Azevedo LF. Exercício aeróbio no tratamento da hipertensão arterial e qualidade de vida de pacientes hipertensos do Programa de
Saúde da Família de Ipatinga. Rev Bras Hipertens. 2010;17(2):78-86.

26. Ishikawa K, Ohta T, Zhang J, Hashimoto S, Tanaka H. Influence of age and gender on exercise training-induced blood pressure reduction in systemic hypertension. Am J Cardiol. 1999;84(2):192-6.

27. Pedrosa R, Holanda G. Correlação entre os testes da caminhada, marcha estacionária e TUG em hipertensas idosas. Rev Bras Fisioter. 2009;13(3):252-6.

28. Pedrosa R, Holanda G. Força muscular respiratória e capacidade funcional em idosas hipertensas com sonolência diurna excessiva. Fisioter Pesqui. 2010;17(2):118-23.

29. Baker MK, Atlantis E, Fiatarone Singh MA. Multi-modal exercise programs for older adults. Age Ageing. 2007;36(4):375-81.

30. Garcia PA, Dias JMD, Dias RC, Santos P, Zampa CC. Estudo da relação entre função muscular mobilidade funcional e nível de atividade física em idosos comunitários. Rev Bras Fisioter 2011;15(1):15-22.

31. Cosme RG, Okuma SS, Mochizuki L. A capacidade funcional de idosos fisicamente independentes praticantes de atividade física. Revista Brasileira de Ciência e Movimento. 2008;16(1):39-46.

32. Oxley JA, Ihsen E, Fildes BN, Charlton JL, Day RH. Crossing roads safely: an experimental study of age differences in gap selection by pedestrians. Accid Anal Prev. 2005;37(5):962-71. 